\title{
Price Dispersion of Hotel Reservation Online: Evidence from Chinese Megacities
}

\author{
Xinglong Xie and Ying Chen \\ Economics \& Management Institute, Xi'an University of Technology, Xi'an PRC \\ long86886@aliyun.com
}

Keywords: Analysis of variance; E-commerce; Online reservation; Price dispersion

\begin{abstract}
The traditional view states that an online company should not post two different prices for the same product on the website, given the price transparency of internet. So, price dispersion in e-commerce is weighted toward vanishing, driving online deals to reach higher market efficiency than offline. This, however, hasn't been conclusive. This study is aimed at dealing with different fares concerning the online reservation of hotels and the factors thereof and providing valuable proposals for designing suitable pricing strategies of turnover maximization. This study delineates the price dispersion literature in connection with E-booking commodities and identifies hotel commodities' inherent attributes. This study accumulates online reservation figures through tracking 23 diverse star-level hotels stemming from 11 websites in Beijing, Shanghai and Guangzhou over the time horizon from 2012 to 2013 to perform an empirical analysis of the four explainable variables' effects on fare dispersion through the approach of analysis of variance. The study finds that room type, hotel ranking, geographic location and time horizon are significant drivers leading to dispersive prices, with star level exerting the strongest impact and three other factors not subject to time. In the three sampling municipalities there exists inconsistency in price dispersion of online booking of a hotel's room is, the maximum for Shanghai's hotel reservation while tiny for Beijing and Guangzhou. This study concludes with pointing out limitations and future-researching fields.
\end{abstract}

\section{Introduction}

In decades, China has experienced a swift development in e-business, with an all-time high of 0.668 billion of netizens, the largest size in the world, websites climbs 4.137 million of websites and a total of 22.3 million of networked domains till July 2015. The country has evolved into a big e-country, suggesting room for growth of e-commerce including business of e-booking guest rooms. Under this background, there has been a fast stead growth in the online reservation business and the travel industry. The trade volume in the country's online travel reservation market reached $\$ 26.24$ billion in 2012 , growing by $32 \%$ on the year-on-year basis, mainly driven by the massive rise in e-booking of hotels and airplane tickets. The trend was estimated to move upward in next year's due to steadfast expansion of the Chinese travel market and increasing demand of Chinese citizens for doing sightseeing.

Currently, the Chinese domestic websites, which provide online reservation of hotel rooms, are classified into three categories: one group is invested by professional e-dealing enterprises, including Ctrip, Elong and Ontrip; companies dealing with offline business, to name but few, China_sss.com, Cytsonline.com and Cnto.com, are interested in undertaking e-commerce activity by creating websites; the last brand of websites are financed from such firms as hotel, airline and entertainment, for instance, Bih.com.cn and Szwwco.com. To be the most renowned, Ctrip, successfully listed On the NASDAQ in Dec. 2003, leads all E- travel agencies, yielding the turnover of RMB 152 billion in 2014 from ticket, hotel and holiday products. Moreover, its growth is projected to carry on for next years as there is an ever-increasing number of middle class in China.

With reference to an increasing quantity of consumers, they have taken advantage of scores of benefits inherent in electronic commerce. Yoon (2002) presented convenience, economic cost, and product diversity as only some of the attributes associated with the e-commerce revolution that has brought about a fundamental revolution in the conceptualization of commercial transactions [1]. 
The tourism industry seems ideally suited to online transaction due to: (1) intangibility of travel products for consumers offered by the industry; (2) inseparability concerning production and consumption (occur at the same time); and (3) perishability and volatility in demand [2]. To go further, hotel, as a product featuring perishability, is urgently calling for various distribution channels to accomplish a high occupancy rate. Room reservation online is acknowledged a flexible resolution to inventory decrease and ultimately serving the rise of turnover. From the consumer perspective, the service of room reservation via the Internet furnishes a rapid and convenient mode of consumption, allowing them to make comparison of room types, prices and facilities in connection with dissimilar inns. So, driven by this attribute, e-booking of a hotel's guest room is tending to frictionless exchange, in which price rates are slip and price dispersion is moving toward shrinking and eventually dies out. In light of this, there has been an optimistic argument that e-business is able to effectively reduce the transaction cost and research cost, whereby to abate suppliers' monopolistic profit and price discrimination and eventually to achieve the optimal disposition of resources. Furthermore, timely delivery of information allows consumers to make a worldwide comparison of quotations by retailers for the same commodity so online markets are close to perfection.

Nevertheless, the data stemming from China's hotel reservations online have failed to confirm this conclusion and diverse websites display a price dispersion regarding the same room of a hotel. Indeed, dispersive fares have existed in online hotel reservation of the same room within the same region. According to the traditional view, an online company shouldn't make it sense to post two diverse prices for the same item on the same website, hoping that some buyers will purchase at the higher price, because the shoppers of a company setting a low and a high price for the same item would very quickly learn to buy only at the low price, given the price transparency of the internet. In this paper, we present evidence of differing prices being posted by the same e-seller on the website for the exactly same room commodities of one hotel and probe into major factors thereof.

The aim of this paper is to contribute to the growing body of literature body of literature on online price dispersion by answering key research questions based on a large number of hotels in Beijing, Shanghai and Guangzhou, three largest metropolises inside Chinese Mainland. Our analysis uses data on 23 inns, which gives our study one of largest samples ever analyzed for the hotel industry. We consider four aspects :21) methodology, (2) room pattern (type), (3) hotel ranking and (4) location. These four aspects allow us to address many of the economic questions set out in existing dispersive fare studies and to compare our results with the existing evidence. To our knowledge, no previous empirical study has sought to get involved in investigating online fare dispersion concerning the three cities' hotel reservations in China. Furthermore, this study also documents a noticeable source of online price dispersion within each single hotel website and thus fills a gap in the literature, which has produced scant empirical evidence of online intra-hotel price dispersion and has mainly focused on the sources of online inter-firm price dispersion.

Our data, covering a phase ranging from June 10, 2012 to April 31, 2013 are taken from 11 websites of online hotel reservation and pertain to 23 inns in Shanghai, Beijing and Guangzhou. Data collection was conducted on Monday and Thursday and the data available on Monday were a meter for Thursday value while Thursday figures were an offer for Sunday. Thus, there have been a total of 70284 observational values to be available.

Our main findings are as follows (1) In line with other empirical studies such as Bachis and Piga (2011)[3], who argue that temporal persistence of intra-firm fare dispersion is an equilibrium phenomenon engendered by the airline's need to manage stochastic demand conciliations for a specific flight, we find that online booking of lodges undergoes price dispersion across the three sampling cities, which stems from house type, hotel ranking, position and time, amid which the hotel ranking exercises the strongest effect whilst the clouts from house sort, star level and location are immune to time change;(2) Star level and room type, being treated as an observable quality-assessment indicator by consumers, are significant contributors to dispersive fares in hotel E-booking. Generally, the more ritzy the room and higher the star, the higher the price dispersion concerning online ordering will become;(3) The empirical analysis exhibits that notwithstanding 
posting fare dispersion, the three sampling metropolises take on dissimilar magnitudes in the amount- the most substantial in the case of Shanghai and almost the same degree in the case of Beijing and Guangzhou; (4) There is a discrepancy over a specific type of houses or certain star hotels, with Shanghai>Guangzhou>Beijing for the same category of guest rooms and Shanghai $>$ Beijing $>$ Guangzhou in relation to the four-star and five-star pubs whereas Guangzhou $>$ Shanghai $>$ Beijing in the case of three-star lodges.

The next section provides literature review concerning dispersive price in the online reservation. Section 3 presents the methodology. The core results and analysis are reported in section 4 . Section 5 concludes with posting main findings and limitations and future research fields.

\section{Literature Review}

The existence of price dispersion, even for homogeneous producers, is among the most replicated findings in empirical economics (Anania and Nistico 2014) [4]. After Stigler's (1961) seminal paper, a rich literature flourished, both theoretical and empirical, analyzing the causes and consequences of such ubiquitous price dispersion [5]. Especially, in the explosion of online transactions across the world, dispersive price has evolved into an issue to trigger great interest and attention from the academic circle.

In China, Zhu (2002) was the earliest exploration of price dispersion and attempted to coin a model covering the interaction between consumer seeking and business decision-making behavior [6]. He found that venders' capability of forming a strategy is declining along with constant maturity in online markets whilst market efficiency is improving. Fao and Tang (2006) showed that E-commerce doesn't necessarily give rise to a drop in the case of price rate and dispersion [7]. Some overseas scholars have concluded that online price dispersion is below offline but others held a differing view (Brynjolfsson and Smith 2000, Ancarani and Shankar 2004) [8,9]. Furthermore, there are considerable quantities of studies to argue that even E-search costs have declined drastically, price dispersion remains in e-transaction activity and doesn't vanish in company with an increasing market ripeness (Lee and Gosain 2002, Ward and Lee 2000) [10, 11].

Much literature attributes dispersive value to three main factors-brand, service and competition. Smith and Brynjolfsson probed into the price dispersion arising from distinct distribution channels under the background of online and offline exchanges. Their result was that consumers prefer to pay a premium of $\$ 2.49$ for making a purchase of books. After having looked into the price data concerning online distribution channel of six pure single-channel and six multi-channel retailers, Tang and Xing concluded that the former are 20-30\% lower in price discrimination than latter. A similar conclusion is found for CDs, books, tapes and household appliances (Tang and Lu 2001, Pan et al.2002) [12, 13].

On the top of the above said contributors, product attribute is acknowledged a significant factor to contribute to online price dispersion. Frequency regarding consumers purchasing a specific commodity can influence its price sensitivity and they are more concerned over regularly traded products, this exercising a binding force upon businesses' pricing strategy. For instance, shoppers usually have a strong motive to hunt for a possible lowest price for prescribed medicines which requires frequent purchase. On this basis, Sorensen discovered that once-purchased drugs are priced on the average or in price divide higher than those that requires buying from month to month. The empirical evidence from Lee and Gosain suggested that there is no considerable dissimilarity in averaging price dispersion for 21 currently prevalent CDs sold online and offline whilst in the case of 22 music CDs which used to be fashionable, the average in price dispersion online is significantly in excess of offline, implying price dispersion is subject to merchandize category (Lee and Gosain 2002) [14].

Amid properties concerning the commodities which have been utilized to address price dispersion in current literature, perishability, a common attribute, has evolved into a primary concern. Products like guest houses tend to be perishable so that hotel management is necessary and imperative to move onto a status of flexible pricing in an attempt to advance a high occupancy rate by virtue of expanding sales channels. Hanks et al argued that a hotel enterprise can gain a high 
profit via adopting price discrimination strategies such as granting discount or allowance to diverse consumer groups whilst Ens' view was that concern should remain over controlling over distributional channels due to a low price elasticity in hotel product demand (Hanks et al.2002, Enz 2003) $[15,16]$.

These studies suffer a flaw that they have ignored the effects on price dispersion concerning online reservation that hotel rating, room type, time and location may wield, merely focusing on hotel products' own temperaments and consequences whereof. The study attempts to fill this gap by resorting to the clouts from location, hotel ranking, room pattern and time span.

\section{Empirical Study}

Website and Hotel Selection. On a basis of travel websites displayed by IwebChoice and Iresearch-2013 China Online Reservation Report, we pitched on 12 websites as a data source, which are universally acknowledged prominent in providing granting e-booking services to hotel customers. During the course of collecting data, some websites such as http://www.365holiday.net have failed to essentially demonstrate quotations in relation to hotel commodities and services so we made an adjustment of all the primeval selected websites to screen out 11 websites as the origin of the real figures for this study (see table 1).

Table 1 Selected websites

\begin{tabular}{|c|c|c|c|}
\hline www.elong.com & big5.ctrip.com & www.ontrip.com.cn & www.e-tour.com.cn \\
\hline www.51ticket.net.cn & trip.sina.com.cn & www.china356.com & www.v222.com \\
\hline www.hzwy.com & www.bizexpress.com & www.goldenholiday.com & \\
\hline
\end{tabular}

Table 2 Chosen hotels

\begin{tabular}{|c|c|c|c|}
\hline Star & Beijing & Shanghai & Guangzhou \\
\hline 3 & $\begin{array}{c}\text { Y.X. Hotel,Tibet hotel, } \\
\text { K.G. hotel }\end{array}$ & $\begin{array}{c}\text { W.M. Hotel, Y. Zh. Hotel, } \\
\text { Post hotel }\end{array}$ & H.Q. Hotel, Olympic hotel \\
\hline 4 & $\begin{array}{c}\text { B.L.hotel } \\
\text { D.F. hotel }\end{array}$ & $\begin{array}{c}\text { Ocean hotel } \\
\text { International hotel }\end{array}$ & $\begin{array}{c}\text { B.Y.hotel, G.Zh.hotel, } \\
\text { Central hotel, Merchant hotel }\end{array}$ \\
\hline 5 & $\begin{array}{c}\text { X.Y.hotel, W.F.J. hotel } \\
\text { Dynasty hotel }\end{array}$ & $\begin{array}{c}\text { J.J.Hotel } \\
\text { Peace Hotel }\end{array}$ & $\begin{array}{c}\text { White Swan hotel } \\
\text { Garden hotel }\end{array}$ \\
\hline
\end{tabular}

Finally, we choose a total of 23 hotels located in Beijing, Shanghai and Guangzhou serving as the source of obscuring figures. Within the same location, one star and two star hotels were ignored with their offers being seldom released on the webs. Additionally, those inns, which are not registered online, are turned down when we obtained access to data for empirical analysis. Eventually, the only those hotels, which have been listed at least five in eleven websites following, are chosen, totaling to 23, 8 in Beijing, 7 in Shanghai and 6 in Guangzhou (refer to table 2).

For per sampling lodge, three kinds of rooms- standard double, luxury double and suite, are pitched on as a researched object. If one inn doesn't have the above said rooms, other types of rooms like economic-typed and luxury suite will be used to substitute them. So, the figures for eight indicators are available-price, date, hotel, rank, location, type, website and weekend.

Methodology. This study is mainly dedicated to dealing with price dispersion concerning online reservation of hotels by virtue of standard deviation regarding the same inn and the same type of room at the same time point. We have recourse to the following model to explore the effects of the two and three dimension interaction terms on price difference as well as type, rank, location and date, which are respectively symbolized by $T, R, L$ and $D$ :

$$
\ln (S D)=\alpha_{0}+\sum_{i=1}^{3} \beta_{i} T_{i}+\sum_{i=1}^{3} \theta_{i} L_{i}+\sum_{i=1}^{3} \psi_{i} R_{i}+\sum_{r=1}^{100} r_{i} D_{i}+A+\varepsilon
$$

Where A denotes an optional interaction term, with a total of three two-dimensional and one 
three-dimensional interactional, $\sum_{i=1}^{3} \beta_{i}=0, \sum_{i=1}^{3} \theta_{i}=0, \sum_{i=1}^{3} \psi_{i}=0, \sum_{i=1}^{100} r_{i}=0$, and $\varepsilon$ is distributed normally, with the average coming to 0. Canton Fair is held twice per year, from April 15 to 20 and Oct. 15 to 30 when room prices rise sharply, which fail to reflect normal price fluctuations so the 20 sets of figures over the two time spans are removed and there are 100 time points to be applied into the empirical analysis.

Empirical Results. In order to shed light onto the impact which type, rank, location, data and interactive terms exert on online price dispersion, we shall take turns to modify selectable interactive terms to test four models through ANOVA(results on the table 3). Models one mainly tests the effects of variables on price gap - room type, hotel rank, location date and date. Model 2 demonstrates that the two-dimensional interactional terms are insignificant with $\mathrm{p}$ being 0.403 , 0.993 and 1.000 so type; hotel ranking and location are not variable along with time. Thus, we run a test following eliminating the three insignificant two-dimensional crossing terms (results on table ). On the basis of model 3, we add one three-dimensional interaction term to produce model 4, which suggests that the three-dimensional chiasmatic term is significant at a high level. Moreover, model 4 has the maximum in the value of adjusted $R^{2}$ so that it is employed by us to perform the empirical analysis. Model 4 demonstrates that room type, hotel rank, location and time all exert a significant effect on price dispersion with their values concerning $\mathrm{p}$ reaching 0.000 , amid which hotel rank's impact is the most dominant for its value $F$ standing at 922.79 . Location $\times$ Rank, Type $\times$ Rank and Location $\times$ Type, the two-dimensional interactive terms, are confirmed to be a momentous contributor to triggering price dispersion as their $\mathrm{F}$ value come at 116.71, 107.15 and 21.94 and are extremely significant. There exists a similar clout for the three dimensional interactional term in function on the dispersive price. The time variable exercises an imperative impact on the gap of price mainly on midweek and weekend, sharper during the peak time and off time when demand disparity gives rise to price fluctuations.

Next, this paper would turn to investigating and gauging the effects on price dispersion of two important elements: the quality and location of an inn.

Quality Effect. The star level of a hotel wields a significant effect on price dispersion in e-booking rooms but differences exist among dissimilar rankings of hotels: the higher the star grade, the more substantial price dispersion will be, Rank5>Rank4>Rank3 ( $\mathrm{P}=0.000)$, enhanced by differing customer groups for hotels with rank differentiations: five stars' target guests, with their aim usually being business trip and expenses born by their firms, are unresponsive to price fluctuations and show solicitude for the quality and brand of a hotel, where they will check in, while, three star customers are more interested in room charge evaluation through online search as expenditures for traveling activity including accommodations are registered to their own accounts, thereby putting three star hotels into Bertrand competition and e-fares at a relatively low level. Consequently, the star rank dissimilarity triggers a distinction in the pricing strategy for hotels with disparate stars: the lower the level, the stronger competition will get and the lower price dispersion will become.

Such a gap could be also confirmed by room types: the more luxury the room, the less responsive consumers will be to prices and the more massive price dispersion will come: Type 3>Type2>Type1 $(\mathrm{P}=0.000)$. This can give rise to formulation of differing pricing tactics for unlike star levels of hotels: a more flexibility in price fluctuation is suitable to high-end inns while the best policy for hotels at a lower level should focus price advantage.

Location Effect. The effects of location on influencing price dispersion are demonstrated by figures 1-2. Explicitly, the price gap in E-booking hotel rooms across Beijing, Shanghai and Guangzhou is found, being the highest in Shanghai whilst not significant in the two other metropolises due to the value for $\mathrm{P}$ equaling to 0.15 , rather marginal. Furthermore, following an investigation of two locality-connected interactive terms with two dimensions, we discover that for the three regions, magnitude in dissimilar ranks and categories of inns is of differentiation, the more bronzer room quality; the more significant regional distinction will exercise consequence. With 
regard to Guangzhou, the cost disparity is sequenced in the lower power line of Rank $5>$ Rank $3>$ Rank 4, and, Type $3>$ Type $2>$ Type 1, with a slight quantity between three-star and four-star hotels.

Shanghai and Beijing have a similar stance-Rank 5> Rank 4>Rank 3, an insignificant quantum of gap between Beijing's standard and luxury rooms. Throughout the three areas, the more luxury the room and higher the hotel rating, the larger price dispersion will be. Nevertheless, it represents discrepancy over a specific type of guest houses or hotels with a certain star level, Shanghai being the largest, Beijing the least and Guangzhou in between for those rooms with the same specification.

A similarity of dispersion is found for the three cities in the case of four-star and five-star pubs while Guangzhou tops, Beijing is at the bottom and Shanghai lies somewhere between in the case of three-star lodges. Obviously, Beijing's price gap is in the excess of Guangzhou concerning the higher level of star hotels, and this is probably because of Beijing as a tourism city, where self-financing consumers represent a large proportion.

Table 3 Testing results covering four models

\begin{tabular}{|c|c|c|c|c|}
\hline & Model 1 & Model 2 & Model 3 & Model 4 \\
\hline Intercept & 64729.51 & 56608.66 & 59439.57 & 57328.03 \\
\hline Type & $489.81(*)$ & $643.04(*)$ & $626904(*)$ & $543.66(*)$ \\
\hline Rank & $1540.49(*)$ & $1140.41(*)$ & $1083.27(*)$ & $1075.24(*)$ \\
\hline Location & $274.12(*)$ & $212.89(*)$ & $237.57(*)$ & $230.93(*)$ \\
\hline Date & $149.18(*)$ & $128.23(*)$ & $124.75(*)$ & $121.53(*)$ \\
\hline Rank $\times$ Location & & $256.02(*)$ & $319.28(*)$ & $271.99(*)$ \\
\hline TypexLocation & & $53.710(*)$ & $47.78(*)$ & $51.12(*)$ \\
\hline Type×Rank & & $254.65(*)$ & $264.28(*)$ & $249.70(*)$ \\
\hline Location $\times$ Date & & $127.34(0.403)$ & & \\
\hline Rank×Date & & $95.33(0.99)$ & & \\
\hline TypexDate & & $38.74(1.000)$ & & \\
\hline Type $\times$ Rank $\times$ Location & & & & $160.06(*)$ \\
\hline Error & 3790.27 & 2924.37 & 3207.67 & 3047.60 \\
\hline Total & 77353.87 & 77353.87 & 77353.87 & 77353.87 \\
\hline Corrected Total & 6128.86 & 6128.86 & 6128.86 & 6128.86 \\
\hline $\mathrm{R}_{\mathrm{ad}}{ }^{2}$ & 0.369 & 0.450 & 0.465 & 0.491 \\
\hline
\end{tabular}

$*$ indicates significant at the $1 \%$ level.

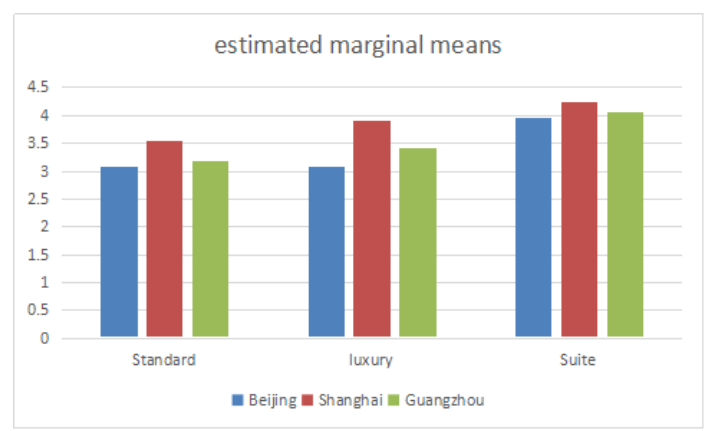

Figure 1

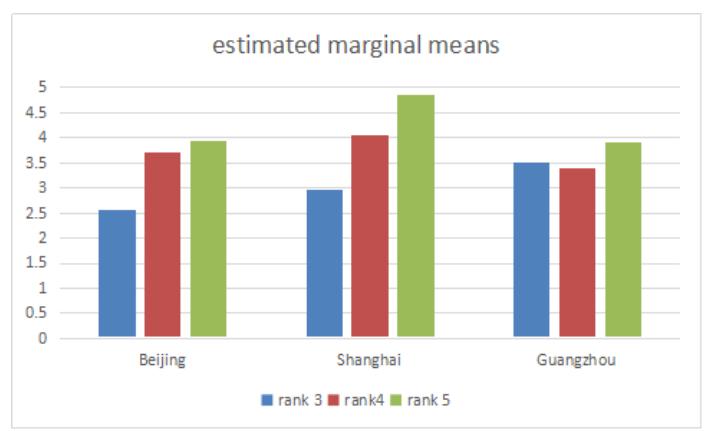

Figure 2

\section{Concluding Remarks}

E-commerce can lead to a sharp reduction of buyer search costs and information asymmetry. Specially, usage of search engines enables purchasers to make comparison of quality, prices and services concerning like commodities at the same time and place. Thus, the online marketplace is tilted to frictionless trade, giving rise to a decrease of price levels, pushing price dispersion to fade 
away and ultimately contributing to a higher efficiency for e-markets than offline. This study is motivated to have an insight into price dispersion in the case of online room booking, contributing to providing a broad evaluation of the effects, on which hotel star grade, room type, date and location exert. We perform a comparative examination of three direct-controlled municipalities by virtue of gleaning detailed figures from 11 websites online. A total of 23 hotels is examined through ANOVA, allowing us to glean a broad range of new insights into the influences upon price gap by the four drivers in the case of hotel e-reservation:(1) Online booking of lodges undergoes price dispersion which stems from house type, hotel ranking, position and time, amid which hotel ranking exercises the strongest effect whilst the clouts from house sort, star level and location are immune to time change;(2) Star level and room type, being an observable quality indicator by consumers, are significant influencing agents. Generally, the more the ritzy rooms and higher the star, the higher the price gap concerning online ordering will become;(3) The empirical analysis exhibits that the three sampling metropolises sustain price differences, which take on the sharpest amount in Shanghai and almost the same degree in both other cities.

Our results provide valuable insights into the competitiveness of hotel price. At the individual-hotel level, the results can be used as the basis for formulating a package of room pricing to achieve the commercial goal projected. With reference to higher star levels of hotels, an appropriately higher charge for the same type of rooms can be considered. For lower-end inns, a lesser fare would increase the occupancy rate by means of attracting and retaining more consumers. For Shanghai-location hotels, management must conduct a deliberate consideration of price dispersion and effects thereof on customers before decision-making. A relatively stable room rate could be proper for hotels, which are positioned in Beijing and Guangzhou.

This study has limitations. Initially, our data is limited to a limited time period from 2012-2013, Although this time horizon offers a unique insight into how dispersive price was moving, it would be desirable to have longer time series which would also the series more recent and more refined units of observations. An additional limitation of this study is that we fail to observe quotations for all hotel retailers on the Internet. Ideally, prices offered by all Internet hotel retailers should be observed albeit there is no reason to confirm that the quotations available in our study are biased with respect to prices offered by the entire market.

Future research could focus on investigating in greater details how market structure, product heterogeneity and time alteration might contribute to prices and price dispersion. Furthermore, since the Interment reveals information about the price sensitivity of customers, retailers not only in hotels but other commodities such as automobile may take advantage of this information to set customized prices for consumers and it would be interesting to conduct a penetrating insight into the impact of these changes on both organization and consumer behaviors.

\section{Acknowledgments}

The authors are thankful to the financial aid from the fund program named "Human Resources' Functioning Mechanism on FDI Technological Transfer and Proposals for Strategies Attracting Foreign Capital” No.2015KRMO98, granted by Shaanxi science\&technology department.

\section{References}

[1] S.J. Yoon:Journal of Interactive Marketing,Vol.16(2002),p47-63.

[2] P. McCole: International Journal of Contemporary Hospitality Management, Vol.14 (2002), p81-87.

[3] B. Enrico and A.P. Claudio: International Journal of Industrial Organization, Vol.29 (2011), p655-667.

[4] G. Anania: Food Policy, Vol.44 (2014), p190-201.

[5] G. Stigler: Political Economy, Vol.69 (1961), p213-225. 
[6] T.Zhu: World Economy, Vol.2(2002),pp12-20.(In Chinese)

[7] H.Fao and F.F. Tang: Inquiry into Economic Issues, Vol.2(2006),p150-155.(In Chinese)

[8] E. Brynjolfsson and M. Smith: Management Science, Vol.46 (2000), p563-584.

[9] F. Ancarani and V. Shankar: Journal of Academic of Marketing Science, Vol.32 (2004), p176-187.

[10]Z. Lee and S. Gosain: Journal of Business Strategies, Vol.19 (2002), p55-71.

[11]M. Ward and M. Lee: Journal of Product and Brand Management, Vol. 9(2000), p6-18.

[12]F.F. Tang and D. Lu: Electronic Markets, Vol.11 (2001), p171-185, 2001.

[13]X.Pan., B.T. Rathchford, and V. Shankar: Journal of Academy of Marketing Science, Vol. 30(2002), p433-445.

[14]Z. Lee and S. Gosain: Journal of Business Strategies, Vol. 19(2002), p55-71..

[15]C.A. Enz: Cornell Hotel and Restaurant Administration Quarterly, Vol. 41(2003), pp4-5.

[16]R.D. Hanks, R.G. Cross, and R.P. Noland: Cornell Hotel and Restaurant Administration Quarterly, Vol. 43(2002), p94-103. 